\title{
Crosstalk between TLR2 and Sphk1 in microglia in the cerebral ischemia/reperfusion-induced inflammatory response
}

\author{
WEI SUN ${ }^{1}$, ZHAOMING DING $^{2}$, SHENGJIE XU $^{3}$, ZHIQIANG SU ${ }^{1}$ and HULUN $\mathrm{LI}^{4}$ \\ ${ }^{1}$ Department of Neurology, The First Affiliated Hospital of Harbin Medical University; \\ ${ }^{2}$ Department of Thyroid Surgery, The Third Affiliated Hospital of Harbin Medical University; \\ Departments of ${ }^{3}$ Pathology, ${ }^{4}$ Neurobiology, Harbin Medical University, Harbin, Heilongjiang 150081, P.R. China
}

Received April 27, 2016; Accepted September 6, 2017

DOI: $10.3892 / \mathrm{ijmm} .2017 .3165$

\begin{abstract}
Stroke is associated with high morbidity and mortality, and much remains unknown about the injury-related mechanisms that occur following reperfusion. This study aimed to explore the roles of Toll-like receptor 2 (TLR2) and sphingosine kinase 1 (Sphk1) in microglial cells in inflammatory responses induced by cerebral ischemia/reperfusion (I/R). For this purpose, C57BL/6 mice were randomly divided into 4 groups as follows: the sham-operated group, the I/R group, the I/R group treated with TLR2 antibody, and the I/R group treated with $N, N$-dimethylsphingosine. Focal cerebral I/R was induced by middle cerebral artery occlusion. Double-labeling immunofluorescence was used to observe the protein expression of TLR2 and Sphk1 in the ischemic brain tissue. Quantitative polymerase chain reaction was performed to determine the mRNA levels of TLR2 and Sphk1 in ischemic brain tissue. Enzyme-linked immunosorbent assay was carried out to detect the protein contents of interleukin (IL)- $1 \beta$, tumor necrosis factor- $\alpha$ (TNF- $\alpha)$, IL-17 and IL-23 in ischemic brain tissue. The results revealed that I/R upregulated TLR2 and Sphk1 expression in microglial cells, and the inhibition of either TLR2 or Sphk1 inhibited the expression of the pro-inflammatory cytokines, IL-1 $\beta$, TNF- $\alpha$, IL-17 and IL-23. Notably, the inhibition of TLR2 activity also decreased Sphk1 expression. These results thus indicate that the activation of microglial cells, via a TLR $2 \rightarrow$ Sphk1 $\rightarrow$ pro-inflammatory cytokine (IL-1 $\beta$, TNF- $\alpha$, IL-17 and IL-23) pathway, may participate in I/R injury.
\end{abstract}

Correspondence to: Dr Zhiqiang Su, Department of Neurology, The First Affiliated Hospital of Harbin Medical University, 23 Youzheng Street, Nangang, Harbin, Heilongjiang 150081, P.R. China

E-mail: zhiqianglsj@126.com

Dr Hulun Li, Department of Neurobiology, Harbin Medical University, 194 Xuefu Street, Nangang, Harbin, Heilongjiang 150081, P.R. China E-mail: hulunli@163.com

Key words: ischemia, reperfusion injury, Toll-like receptor 2, sphingosine kinase 1

\section{Introduction}

Stroke is a serious threat to human health (1), and ischemia/ reperfusion (I/R) injury (IRI) is an important pathophysiological mechanism of ischemic stroke (2). Although the mechanisms of IRI are complex, increasing evidence indicates that the immune inflammatory response plays an important role in this process $(2,3)$. Microglial cells are residential macrophages in the central nervous system (CNS). As the first defensive line against pathogenic microorganisms, microglial cells provide innate immune signaling and adaptive immune responses (4). Microglial activation is considered to be a hallmark of neuroinflammation. It is well documented that the activation of microglia in various neurodegenerative diseases contributes to neuroinflammation through the release of large amounts of pro-inflammatory cytokines. Some of these are neurotoxic, suggesting that activated microglia participate in acute brain injury and cerebral ischemia $(5,6)$.

Toll-like receptors (TLRs) are a family of transmembrane receptors that are able to recognize pathogen-associated molecular patterns. As essential components of the microglial innate immune response, TLRs induce the production of neurotoxic factors from microglia, contributing to neuronal damage $(7,8)$. The activation of TLR2 leads to the activated microglial expression of pro-inflammatory cytokines, including interleukin (IL)-23, IL-17, IL-1 $\beta$ and tumor necrosis factor- $\alpha$ (TNF- $\alpha)$ in various neuroimmunological diseases, such as multiple sclerosis, experimental autoimmune encephalomyelitis and IRI (4,9-12).

Sphingosine-1-phosphate (S1P) can regulate cell proliferation, survival, apoptosis, migration and $\mathrm{Ca}^{2+}$ osmotic balance (13). The S1P signaling pathway in the CNS plays a role in important processes, such as neurotransmitter release, proliferation and cell survival (14). As an intracellular second messenger and an extracellular ligand that interacts with $\mathrm{G}$ protein-coupled receptors $(15,16), \mathrm{S} 1 \mathrm{P}$ regulates peripheral macrophages and immune cell function (17-19), which are involved in major pathophysiological mechanisms in autoimmune diseases of the CNS $(20,21)$. Sphingosine kinase (Sphk) is a key enzyme in S1P synthesis $(22,23)$ and plays an important role in human immune cell chemotaxis and wound healing processes. It has two isoforms, Sphk1 and Sphk2 $(20,24)$. Sphk1 is the main source of Sphk activity in brain tissue $(25,26)$. BV2 microglial cells 
and purified microglia from primary cultures have been shown to express some or all of the five S1P receptors (27). The Sphk1/ S1P signaling pathway has been shown to be involved in the inflammation of peripheral immune cells and BV2 cells through autocrine/paracrine pathways and to promote the production of TNF- $\alpha$, IL-1 $\beta$ and nitric oxide (NO) through the nuclear factor- $\kappa \mathrm{B}(\mathrm{NF}-\kappa \mathrm{B})$ pathway $(20,28,29)$. The Sphk1-specific inhibitor, $N, N$-dimethylsphingosine (DMS), or Sphk1 knockout can inhibit microglial cells expressing NF- $\kappa$ B, TNF- $\alpha$, IL- $1 \beta$ and inducible nitric oxide synthase (iNOS), as well as reduce TNF- $\alpha$ and NO release $(28,29)$. Resting microglia typically express very low levels of sphingolipid metabolities, including Sphk1 (30). Exposure to Lipopolysaccharide (LPS) or hypoxia upregulates Sphk1 expression in amoeboid microglia and BV2 cells, and Sphk1 plays a crucial role in the early stages of CNS inflammation $(28,29)$.

It has been suggested that TLR2 in microglia mediates the activation of the innate immune system by the production of pro-inflammatory cytokines in cerebral I/R (12). Sphk1 in microglia is involved in hypoxic brain damage and inflammation (29). Moreover, TLR2 signaling results in NF-KB formation and then induces the production of pro-inflammatory signals, such as IL-1 $\beta$ (31-34). Sphk1 is involved in LPS-induced NF-kB activation, and DMS can block LPS-stimulated NF-KB expression (35). Based on this evidence, we hypotheseized that TLR2 is closely associated with Sphk1 in activated microglial cells and is involved in the inflammatory response following cerebral I/R. In the present study, we assessed the TLR2 and Sphk1 expression levels in activated microglia during the course of cerebral I/R. We then examined the effect of the TLR2 and Sphk1 on the release of the pro-inflammatory cytokines, IL-1 $\beta$, TNF- $\alpha$, IL-17 and IL-23. We also explored the crosstalk between TLR2 and Sphk1.

\section{Materials and methods}

Animals. Clean grade healthy male C57BL/6 mice (10-12 weeks old, weighing 25-30 g) were purchased from Beijing Vital River Laboratory Animal Technology Co., Ltd. (Beijing, China). The mice were housed in an animal room that was sealed and sterilized by ultraviolet (UV) light irradiation, room temperature $27^{\circ} \mathrm{C}$ and $40 \%$ humidity. Mouse feed, litter and drinking water were autoclaved $\left(120^{\circ} \mathrm{C}, 40 \mathrm{~min}\right)$. The mice were randomly divided into a sham-operated group ( $\mathrm{n}=54)$, an I/R group $(\mathrm{n}=54)$, an I/R + TLR2 antibody group $(n=36)$, and an I/R + DMS group $(n=36)$. Each of these groups was randomly divided into subgroups of ischemia for $1 \mathrm{~h}$ followed by reperfusion for 12, 24 or $48 \mathrm{~h}$. In the sham-operated and I/R groups, the mice in each subgroup (I/R 12-h subgroup, $\mathrm{n}=18$; I/R 24-h subgroup, $\mathrm{n}=18$; I/R 48-h subgroup, $n=18$ ) were separately used for immunohistochemistry $(n=6)$, fluorescence quantitative polymerase chain reaction $(\mathrm{PCR})(\mathrm{n}=6)$ and enzyme-linked immunosorbent assay (ELISA) $(n=6)$. In the I/R + TLR2 antibody and I/R + DMS groups, the mice in each sub-group (I/R 12-h subgroup, $n=12$; I/R 24-h subgroup, $\mathrm{n}=12$; I/R 48-h subgroup, $\mathrm{n}=12$ ) were separately used for fluorescence quantitative PCR $(n=6)$ and ELISA ( $n=6)$. This study was approved by the Ethics Board of the First Affiliated Hospital of Harbin Medical University, Harbin, China and all animal experiments were performed in compliance with the principles and procedures outlined in the Care and Use of Laboratory Animals guidelines, which is published by the China National Institute of Health and approved by the Institutional Animal Care and Use Committee.

Reagents and antibodies. Mouse anti-TLR2 monoclonal antibody [T2.5] (ab59711), mouse anti-Iba1 monoclonal antibody (ab15690; used as marker for microglia) and mouse anti-glial fibrillary acidic protein (GFAP) monoclonal antibody (ab10062) were purchased from Abcam (Cambridge, UK); rabbit anti Sphk1 polyclonal antibody (sc-48825) and rabbit anti-TLR2 polyclonal antibody (sc-10739) were purchased from Santa Cruz Biotechnology, Inc. (Santa Cruz, CA, USA); fluorescence fluorescein isothiocyanate (FITC)labeled goat anti-mouse secondary antibody (ZF-0312) and fluorescent rhodamine-labeled goat anti-rabbit secondary antibody (ZF-0316) were purchased from Beijing Zhongshan Golden Bridge Technology Co. (Beijing, China); the Ultrapure RNA extraction kit (CW0581), HiFi-MMLV cDNA First Strand synthesis kit (CW0744), UltraSYBR Mixture (with Rox) (CW0956), and DNase I (CW2090A) were purchased from Beijing Kangwei Century Biotechnology Co. (Beijing, China); immunoassay kits (IL-23, IL-17, IL-1, TNF- $\alpha$, no. 870257) were purchased from LightArray Biotech Co. (Shanghai, China); and DMS (62575) was purchased from Cayman Chemical (Ann Arbor, MI, USA).

Establishment of focal cerebral I/R model. The suture method was used to occlude the cerebral middle artery of the mice to establish a focal cerebral I/R model. Briefly, $10 \%$ chloral hydrate (intraperitoneal injection of $3.5 \mathrm{ml} / \mathrm{kg}$ body weight) was used to anesthetize the mice, and the carotid artery, external carotid artery and internal carotid artery were then isolated and exposed. A monofilament nylon wire coated with poly-D-lysine (diameter $0.2 \mathrm{~mm}$ ) was inserted into the internal carotid artery through the external carotid artery for approximately $10-12 \mathrm{~mm}$ to induce ischemia in the middle cerebral artery of the brain. The wire was removed after $1 \mathrm{~h}$ to achieve reperfusion. Following $45 \mathrm{~min}$ of ischemia, the mice in the I/R + TLR2 antibody group were injected with TLR2 antibody [T2.5] (0.05 $\mu \mathrm{g} / \mathrm{mouse})$ through the tail vein, and the mice in the $\mathrm{I} / \mathrm{R}+\mathrm{DMS}$ group received intraperitoneal injections of DMS $(400 \mu \mathrm{g} / \mathrm{kg})(29,64)$. In the sham-operated group, a wire was inserted into the carotid artery, but was immediately pulled out after encountering any resistance. A thermal blanket was used to maintain rectal temperature within $37 \pm 1^{\circ} \mathrm{C}$.

Immunohistochemistry. The double-label immunofluorescence method was used to observe the expression of TLR2 and Sphk1 in microglial cells during the process of cerebral I/R. Each group of mice were reperfused for 12,24 or $48 \mathrm{~h}$, then anesthetized with an intraperitoneal injection of $10 \%$ chloral hydrate $(3.5 \mathrm{ml} / \mathrm{kg}$ body weight) before they were perfused with $4 \%$ paraformaldehyde $(\mathrm{pH} 7.4)$. The brain tissues were removed and stored at $-80^{\circ} \mathrm{C}$. A microtome cryostat was used to prepare continuous sections, and the slice thickness was approximately $4 \mu \mathrm{m}$. The slices were mounted on glass plates pre-coated with $2 \%$ APES, fixed with acetone for $1 \mathrm{~min}$, then placed in a $4^{\circ} \mathrm{C}$ thermostatic showcase for storage. The sections were then washed in $0.01 \mathrm{~mol} / 1$ phosphate-buffered saline (PBS, $\mathrm{pH} 7.4$ ) for $5 \mathrm{~min}$, and goat serum was used to 
prevent non-specific antibody binding to the tissue. The slices were placed under room temperature in a wet box for $30 \mathrm{~min}$, followed by overnight incubation with primary antibodies at $4^{\circ} \mathrm{C}$. The corresponding secondary antibodies were incubated after washing with PBS. Images of the tissue sections were acquired using a fluorescence microscope (DMI6000B; Leica, Wetzlar, Germany) at a magnification of x200.

Fluorescence quantitative PCR. A fluorescence quantitative PCR method was used to measure the mRNA levels of TLR2 and Sphk1 in ischemic brain tissue. Each group of mice after 12,24 or $48 \mathrm{~h}$ of reperfusion were then anesthetized with $10 \%$ chloral hydrate $(3.5 \mathrm{ml} / \mathrm{kg}$ body weight) by intraperitoneal injection. The ischemic side brain tissue was storeed at $-80^{\circ} \mathrm{C}$ in a low temperature freezer for future use. Primers for the real-time PCR detection of the target gene were designed and synthesized by Beijing Kangwei Century Biotechnology Co. and were as follows: TLR2 forward, CAGTCCCAAAGTCT AAAGTC and reverse, CTACGGGCAGTGGTGAAAAC, amplification product 166 bp; Sphk1 forward, GGAACC AGTAGAATGCCCTC and reverse, GGTTCTTCCGTTCGG TGAGT, amplification product $173 \mathrm{bp}$. An ultrapure RNA extraction kit (cat no. CW0581; CW Bio. Co., Ltd., Beijing, China) was used to extract total RNA amount from the tissue. Samples containing $5 \mu \mathrm{l}$ RNA were assessed with $1 \%$ agarose gel electrophoresis, and a HiFi-MMLV cDNA first-strand synthesis kit (cat no. CW0744; CW Bio. Co., Ltd.) was used to perform reverse transcription. Using an LC-480II quantitative PCR machine, the $2^{-\Delta \Delta \mathrm{CT}}$ method was used for the quantitative analysis of related data. Each sample was analyzed in duplicate.

ELISA. A multi-factor protein biomarker detection system (purchased from LightArray Biotech Co.) was used to measure the protein contents of IL-23, IL-17, IL-1 $\beta$ and TNF- $\alpha$ in the ischemic brain tissue. Following reperfusion for 12,24 or $48 \mathrm{~h}$, each group of mice was anesthetized with $10 \%$ chloral hydrate $(3.5 \mathrm{ml} / \mathrm{kg}$ body weight $)$ by intraperitoneal injection, and the ischemic brain tissue was collected and stored at $-80^{\circ} \mathrm{C}$. Mouse brain tissue was homogenized, then $50 \mu \mathrm{l}$ standard sample or $50 \mu \mathrm{l}$ test samples were incubated under $20-25^{\circ} \mathrm{C}$ (200 rpm for $3 \mathrm{~h}$ ). Subsequently, $50 \mu \mathrm{l}$ biotinylated antibody reagent were added to each well and incubated at $20-25^{\circ} \mathrm{C}$ (200 rpm for $\left.30 \mathrm{~min}\right)$. This was followed by the addition of $50 \mu \mathrm{l}$ streptavidin-biotin-horseradish peroxidase reagent and incubated the mixtures at $20-25^{\circ} \mathrm{C}$ (200 rpm for $30 \mathrm{~min}$ ). Finally, $50 \mu 1$ peroxide and SuperSignal Luminol/Enhancer mixtures were added to each well and the fluorescence was measured using a CCD camera. A Cirascan scanning and analysis system (Aushon BioSystems, Inc., Billerica, MA, USA) was used to scan the images, and CIRAS multiple analysis system software was employed to analyze and calculate the light signal density in the image. Each sample was analyzed in duplicate.

Statistical analysis. In this study, the immunofluorescence quantitative PCR and ELISA results are expressed as mean \pm SD. Statistical analysis was evaluated using one-way analysis of variance (ANOVA; SPSS version 19.0; IBM, Armonk, NY, USA). A value of $\mathrm{p}<0.05$ was considered to indicate a statistically significant difference.

\section{Results}

TLR2 is expressed in microglia in response to cerebral $I / R$ and is unaffected by Sphk1. Double immunofluorescence labeling was used to observe the co-expression of TLR2/Iba1 and TLR2/GFAP in the brain tissue of the sham-operated and I/R groups. Both of these exhibited green fluorescence, as shown in Fig. 1, whereas TLR2 exhibited red fluorescence. All the images were taken from the peri-infarct cortex at 12, 24, and $48 \mathrm{~h}$ following cerebral I/R, and the same area was assessed in the sham-operated group. The majority of TLR2-positive cells also expressed Iba1 (marker for microglia), while TLR2 did not co-localize with GFAP in any subgroup of the sham-operated or I/R groups. Although Iba1-positive cells were present, no TLR2 signal was observed in sham-operated mice. In the I/R group, TLR2-positive cells were found in the peri-infarct tissue. Fewer were observed in the I/R 12-h subgroup, higher levels were noted in the I/R 24-h subgroup, and slightly lower levels were noted in the I/R 48-h subgroup. These results suggested that cerebral I/R may activate microglia and sequentially induce the expression of TLR2, which is important for inflammatory responses.

The results of fluorescence quantitative PCR for TLR2 revealed that I/R upregulated the mRNA expression level of TLR2. Compared with sham-operated mice, the TLR 2 mRNA level in the I/R brain tissue was higher at all time points $(\mathrm{p}<0.05)$. Moreover, the TLR2 mRNA levels in both the I/R 24- and 48-h subgroups were higher than those in the 12-h subgroup $(\mathrm{p}<0.05)$, although no significant differences were observed between them at 24 and $48 \mathrm{~h}(\mathrm{p}>0.05)$. The Sphk1-specific inhibitor, DMS, was used to inhibit Sphk1 activity and to examine the effects of Sphk1 on TLR2. The data demonstrated that DMS did not affect the TLR2 levels in the I/R group ( $p>0.05$ ) (Fig. 2).

Sphk1 is expressed in microglia in response to cerebral $I / R$ and is dependent on TLR2. Immunofluorescence double labeling was used to observe the co-expression of Sphk1/Ibal and Sphk1/GFAP in brain tissue from each group (Fig. 3). All the images were taken from the peri-infarct cortex of I/R mice, and the same area was observed in the sham-operated group. The results were similar to those obtained for TLR2; the majority of Sphk1-positive cells also expressed Iba1, while Sphk1 did not co-localize with GFAP in any subgroup of the sham-operated or I/R groups. Although the Iba1-positive cells were present, no Sphk1 was observed in the sham-operated mice. In the I/R group, Sphk1-positive cells appeared after $12 \mathrm{~h}$, peaked at $24 \mathrm{~h}$ and slightly decreased at $48 \mathrm{~h}$. These results suggested that cerebral I/R may activate microglia and sequentially induce the expression of Sphk1, which showed temporal dynamics consistent with TLR2.

The data of fluorescence quantitative PCR for Sphk1 indicated that I/R led to an increase in Sphk1 mRNA expression. Similar to the results of TLR2, the Sphk1 mRNA levels in sI/R mice were higher than those in the sham operation group at any time-point $(\mathrm{p}<0.05)$. TLR2 mRNA increased after $12 \mathrm{~h}$ reperfusion, peaked at $24 \mathrm{~h}$, and slightly decreased at $48 \mathrm{~h}$ compared with $24 \mathrm{~h}$. Anti-TLR 2 monoclonal antibody was used to inhibit TLR2 activity and to examine the effects of TLR2 on Sphk1. Notably, TLR2 downregulated the Sphk1 mRNA levels both in the 12- and 24-h I/R subgroups $(\mathrm{p}<0.05)$. However, TLR2 did not have any significant effects on the Sphk1 levels in the 48-h I/R subgroup ( $\mathrm{p}>0.05$ ) (Fig. 4). 

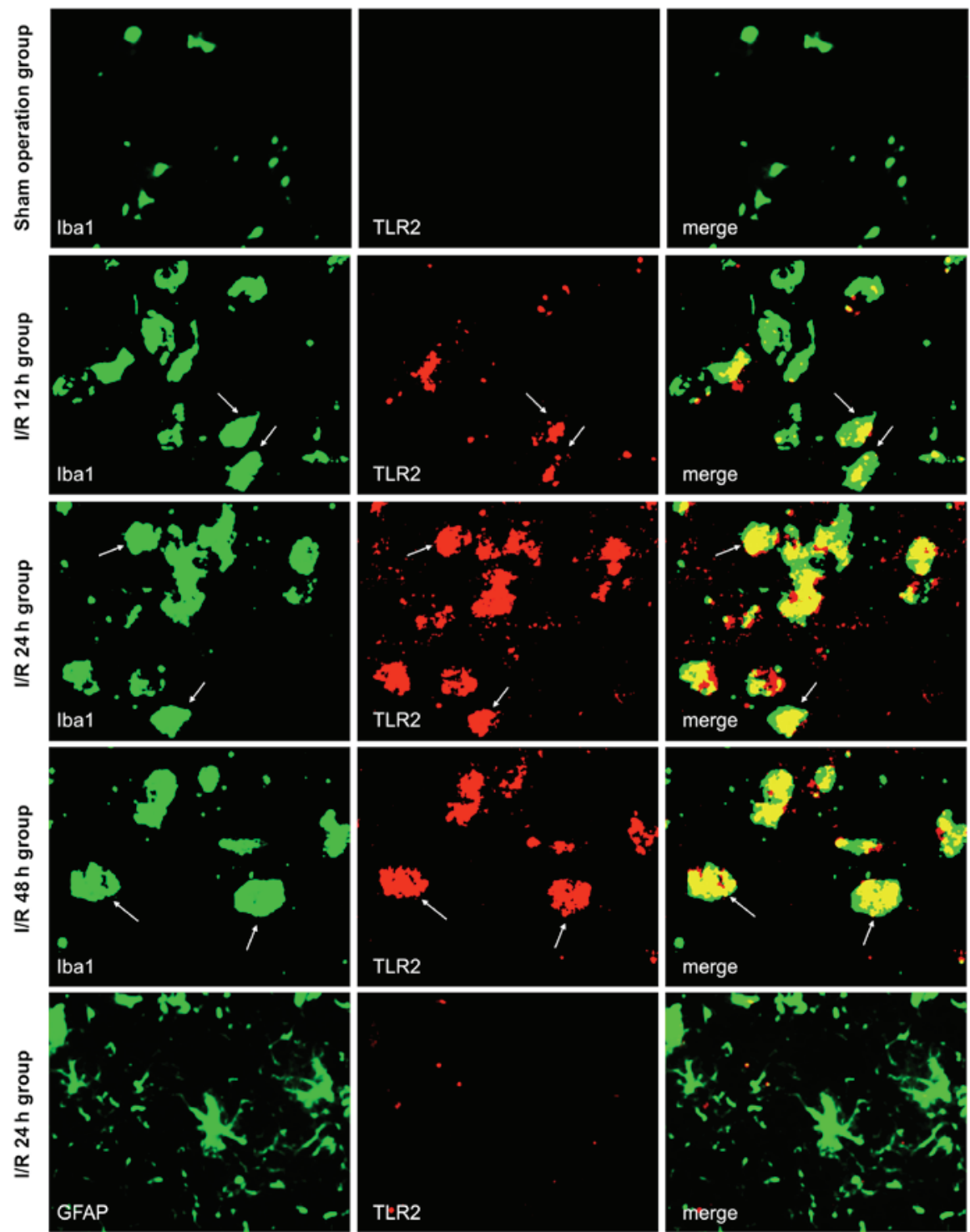

Figure 1. Increased Toll-like receptor 2 (TLR2) expression in tissues from mice subjected to cerebral ischemia/reperfusion (I/R) (magnification, x200). Tissues were double-labeled with TLR2 (red) and Iba1 or GFAP (green). Double-immunofluorescence labeling was analyzed under a fluorescence microscope. White arrows represent protein-positive microglia. The subgroups of the sham-operated group were not differentiated, since the results among the different time points were basically the same.

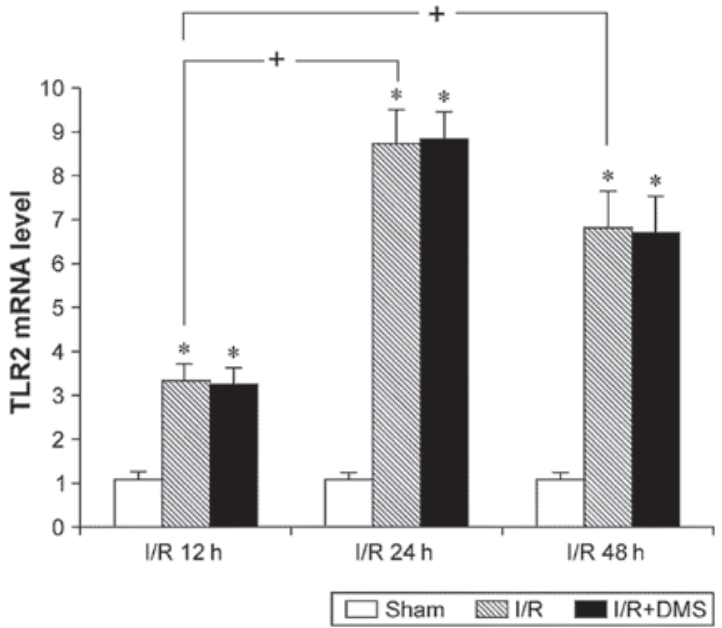

Figure 2. Toll-like receptor 2 (TLR2) mRNA levels in tissue from mice subjected to cerebral ischemia/reperfusion (I/R). Each bar represents the means $\pm \mathrm{SD}$ of the data from separate a subgroup. One-way ANOVA was used for the data analysis. ${ }^{*} \mathrm{p}<0.05$ compared with the sham-operated group; ${ }^{+} \mathrm{p}<0.05$ between any two subgroups with cerebral I/R at different time points.
Suppression of either TLR2 or Sphk1 inhibits the generation of pro-inflammatory cytokines following $I / R$. To further confirm the roles of TLR2 and Sphk1 in I/R-induced inflammation, the IL- $\beta$, TNF- $\alpha$, IL-17 and IL-23 contents in brain tissue from each group were determined. The results revealed that IL-1 $\beta$ was expressed at significantly higher levels in the ischemic brain tissue after 12 or $24 \mathrm{~h}$ of reperfusion compared with the sham-operated group $(\mathrm{p}<0.05)$. However, no significant differences were observed between the sham-operated group and the $48-\mathrm{h} \mathrm{I} / \mathrm{R}$ subgroup ( $\mathrm{p}>0.05$ ). Although the IL-1 $\beta$ level in the 12-h I/R subgroup appeared higher than that in the 24-h I/R subgroup, the difference was not significant $(\mathrm{p}>0.05)$. Importantly, treatment with TLR2 antibody or DMS significantly decreased the IL-1 $\beta$ content in the samples from the the 12- and 24-h I/R subgroups ( $\mathrm{p}<0.05$ ) (Fig. 5).

Cerebral I/R significantly increased the expression of TNF- $\alpha$ at any time point $(p<0.05)$. The TNF- $\alpha$ level in the I/R group increased at $12 \mathrm{~h}$ of reperfusion, peaked at $24 \mathrm{~h}$ of 

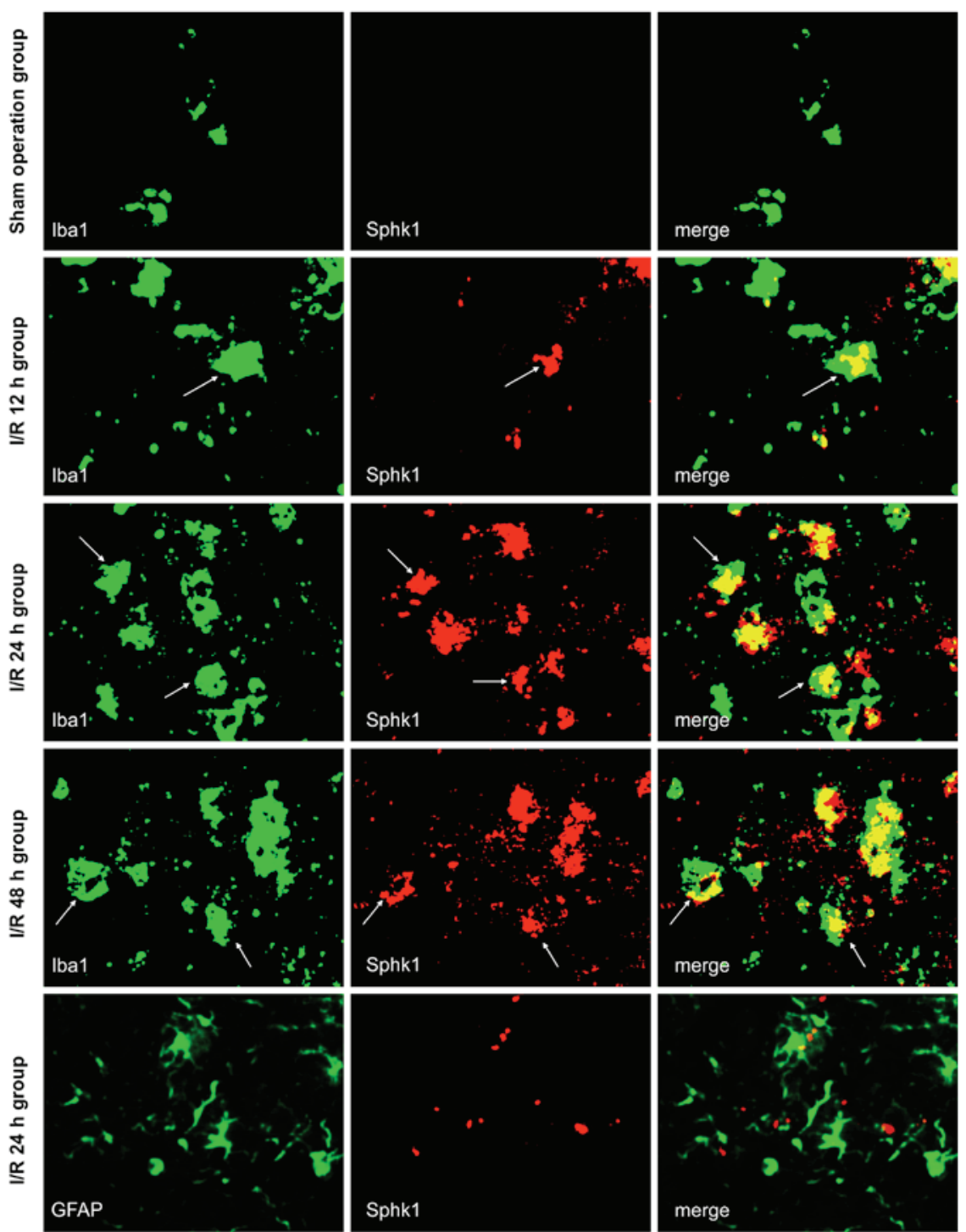

Figure 3. Increased sphingosine kinase 1 (Sphk1) expression in tissues from mice subjected to cerebral ischemia/reperfusion (I/R) (magnification, x200). Tissues were double-labeled with Sphk1 (red) and Ibal or GFAP (green). Double-immunofluorescence labeling was analyzed under a fluorescence microscope. White arrows represent protein-positive microglia. The subgroups of the sham-operated group were not differentiated, since the results among the different time points were basically the same.

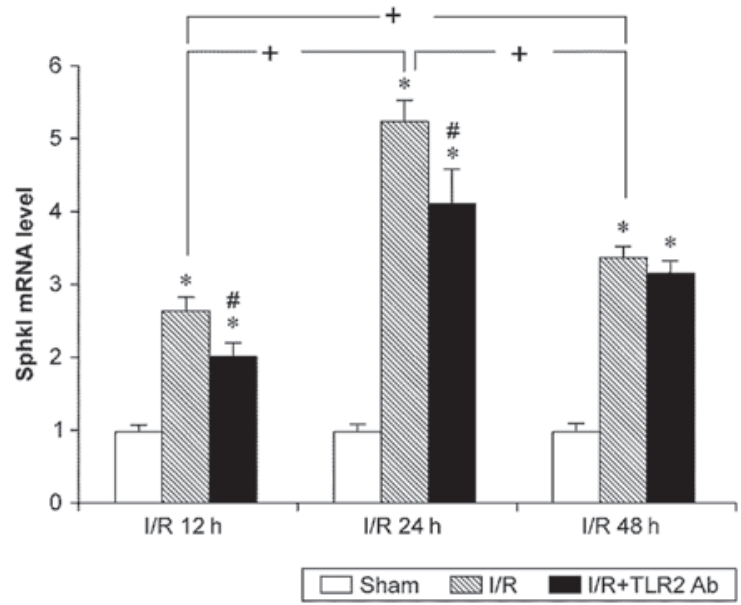

Figure 4. Sphingosine kinase 1 (Sphk1) mRNA levels in tissue from mice subjected to cerebral ischemia/reperfusion (I/R). Each bar represents the means \pm SD of the data from separate subgroups. One-way ANOVA was used for the data analysis. ${ }^{*} \mathrm{p}<0.05$ compared with the sham-operated group; ${ }^{\#} \mathrm{p}<0.05$ compared to the I/R group at the same time point; ${ }^{+} \mathrm{p}<0.05$ between any two cerebral I/R subgroups at different time points. reperfusion, and began to decrease at $48 \mathrm{~h}$ after reperfusion. Treatment with both TLR2 antibody and DMS reduced the TNF- $\alpha$ level in the ischemic brain tissue in the I/R group at $24 \mathrm{~h}(\mathrm{p}<0.05)$. Nonetheless, neither TLR2 antibody nor DMS had any effects on the TNF- $\alpha$ level in the 12-h subgroup or the 48-h subgroup (Fig. 6).

IL-17 expression levels in mouse brain tissue were measured using ELISA, and the results revealed that I/R significantly increased IL-17 expression $(\mathrm{p}<0.05)$. The upregulated IL-17 expression appeared after $12 \mathrm{~h}$, peaked at $24 \mathrm{~h}$, and the levels at $48 \mathrm{~h}$ were similar to those at $12 \mathrm{~h}(\mathrm{p}<0.05)$. Samples from the mice treated with TLR 2 antibody or DMS showed significantly decreased levels of IL-17 at $24 \mathrm{~h}(\mathrm{p}<0.05)$. Conversely, neither TLR2 antibody nor DMS altered IL-17 expression at 12 or $48 \mathrm{~h}$ (p>0.05) (Fig. 7).

The IL-23 content was low in the brain tissue of the sham-operation group and was upregulated significantly by I/R (p<0.05). Similar to IL-17, the IL-23 levels increased at $12 \mathrm{~h}$ 


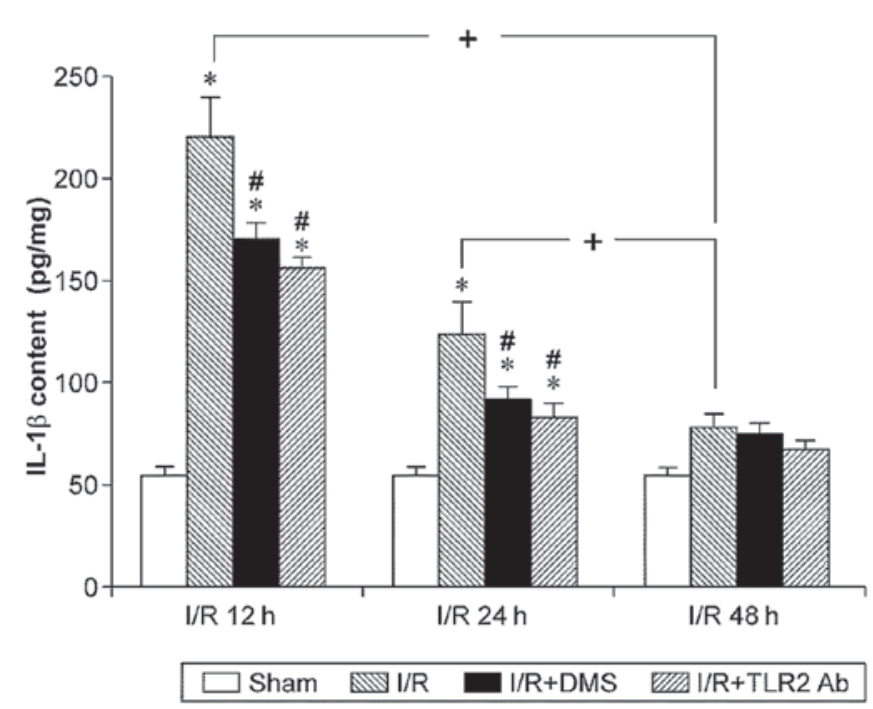

Figure 5. Interleukin-1 (IL-1 $\beta$ ) levels in tissue from mice subjected to cerebral ischemia/reperfusion $(I / R)$. Each bar represents the means \pm SD of the data from separate subgroups. One-way ANOVA was used for the data analysis. " $\mathrm{p}<0.05$ compared with the sham-operated group; ${ }^{*} \mathrm{p}<0.05$ compared with the same time point in the I/R group; ${ }^{+} \mathrm{p}<0.05$ between any two I/R subgroups at different time points.

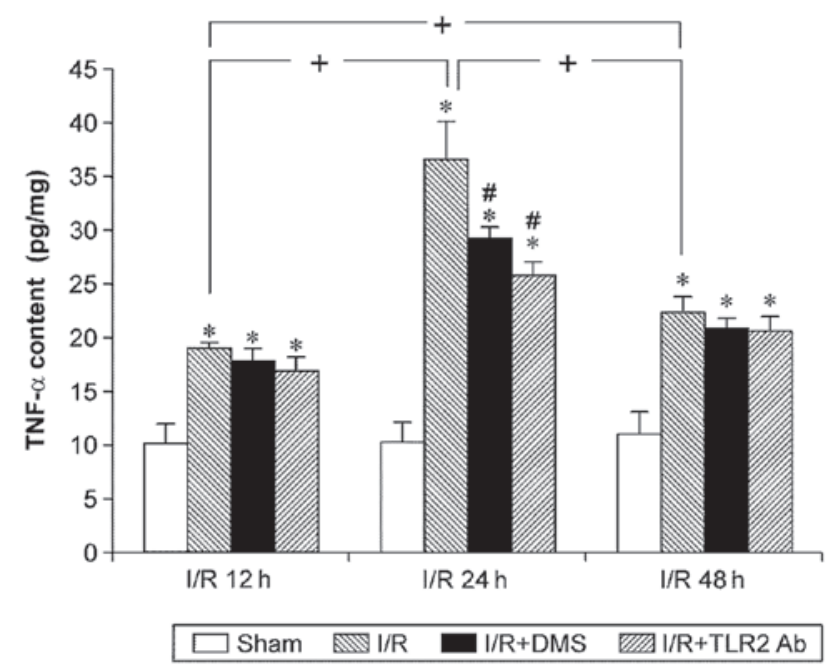

Figure 6. Tumor necrosis factor- $\alpha$ (TNF- $\alpha$ ) levels in tissue from mice subjected to cerebral ischemia/reperfusion (I/R). Each bar represents the means $\pm \mathrm{SD}$ of the data from separate subgroups. One-way ANOVA was used for the data analysis. ${ }^{*} \mathrm{p}<0.05$ compared with the sham-operated group; ${ }^{\#} \mathrm{p}<0.05$ compared with the same time point in the I/R group; ${ }^{+} \mathrm{p}<0.05$ between any two $\mathrm{I} / \mathrm{R}$ subgroups at different time points

of reperfusion, peaked at $24 \mathrm{~h}$, and began to decline at $48 \mathrm{~h}$ of reperfusion $(\mathrm{p}<0.05)$. TLR2 antibody downregulated the IL-23 levels in each subgroup $(\mathrm{p}<0.05)$. Moreover, DMS only reduced the IL-23 content in the 24-h subgroup ( $\mathrm{p}<0.05$ ) (Fig. 8).

\section{Discussion}

The primary aim of this study was to determine the interaction between TLR2 and Sphk1 in microglia following cerebral I/R. We confirmed the effects of TLR2 and Sphk1 on the inflammatory response induced by I/R. Both TLR2 and Sphk1 were primarily expressed in microglia and were upregulated by cerebral I/R. In addition, TLR2 and Sphk1 elevated the levels

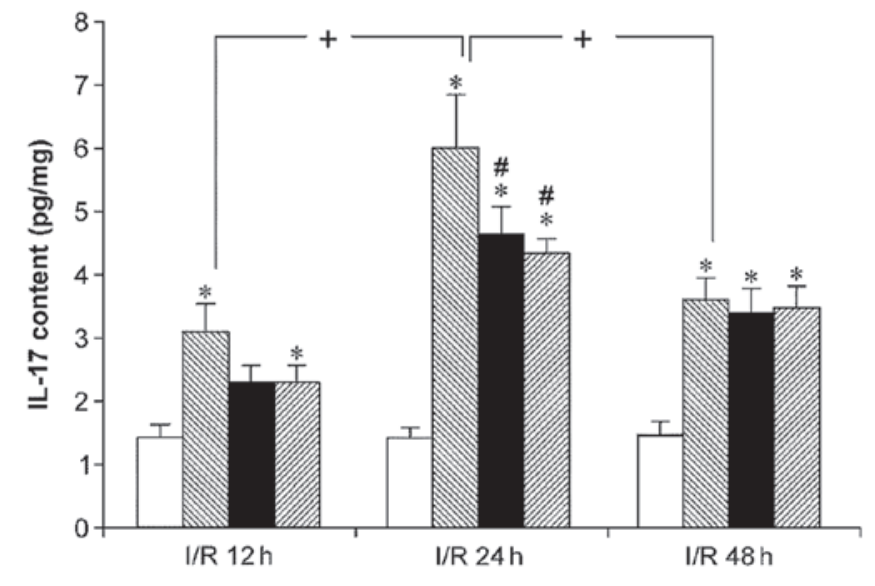

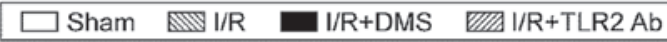

Figure 7. Interleukin-17 (IL-17) levels in cerebral ischemia/reperfusion (I/R) tissue. Each bar represents the means $\pm \mathrm{SD}$ of the data from separate subgroups. One-way ANOVA was used for the data analysis. "p $<0.05$ compared with the sham-operated group; ${ }^{\#} \mathrm{p}<0.05$ compared with the same time point in the $\mathrm{I} / \mathrm{R}$ group; ${ }^{+} \mathrm{p}<0.05$ between any two I/R subgroups at different time points.

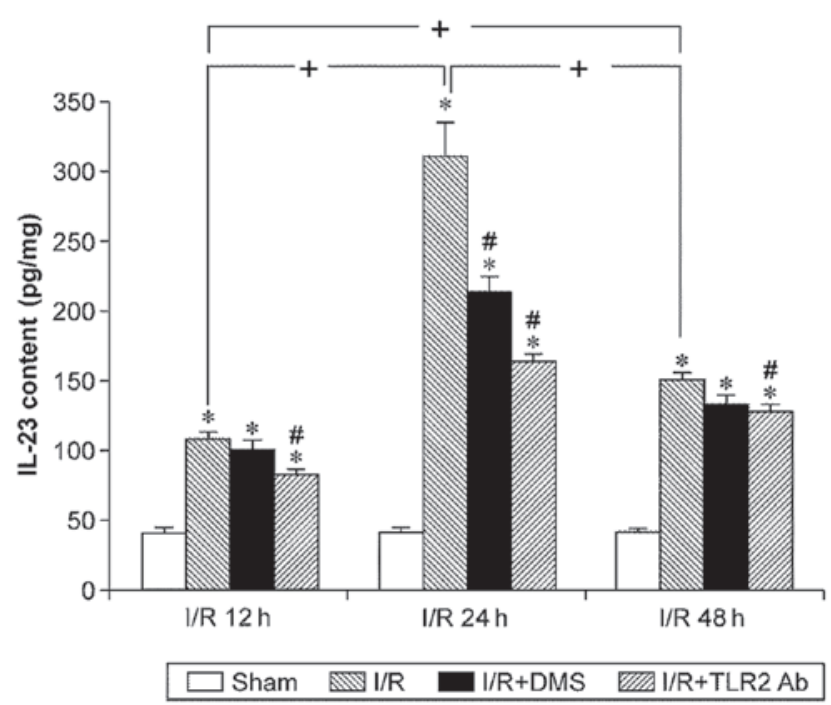

Figure 8. Interleukin-23 (IL-23) levels in cerebral ischemia/reperfusion (I/R) tissue. Each bar represents the means $\pm \mathrm{SD}$ of the data from separate subgroups. One-way ANOVA was used for the data analysis. ${ }^{*} \mathrm{p}<0.05$ compared with the sham-operated group; ${ }^{\#} \mathrm{p}<0.05$ compared with the same time-point in the I/R group; ${ }^{+} \mathrm{p}<0.05$ between any two cerebral I/R subgroups at different time points.

of pro-inflammatory cytokines, including IL- $\beta$, TNF- $\alpha$, IL-17 and IL-23. Furthermore, as the upstream factor of Sphk1, TLR2 regulated the expression of microglial Sphk1 in cerebral $\mathrm{I} / \mathrm{R}$. Therefore, activated microglial cells may be involved in cerebral IRI through the TLR2/Sphk1/pro-inflammatory cytokine pathway.

Microglia are currently considered a double-edged sword. Activated microglia swallow infiltrating neutrophils to protect neurons through the release of neurotrophic factors and antiinflammatory cytokines $(7,36)$. In neuroinflammatory diseases, excessive activation of microglial cells can result in the release of large amounts of cytotoxic factors, such as peroxides, NO, TNF- $\alpha$, free radicals, adhesion molecules and cytokines, which 
induce neuronal damage (37-41). Microglial activation is an early response to brain ischemia. Microglia proliferate and migrate to the sites of injury and induce a non-specific innate immune response that may exacerbate acute ischemic injury (42). In this study, activated microglia infiltrated the ischemic brain tissue and expressed TLR2 and Sphk1. Both TLR2 and Sphk1 separately induced the release of pro-inflammatory cytokines, including IL- $\beta$, TNF- $\alpha$, IL-17 and IL-23 (Figs. 5-8). These results suggest that cerebral I/R induces microglial activation, which may mediate an inflammatory response to aggravate cerebral IRI.

The ischemia-induced damage of adjacent cells is detected by microglial receptors, such as TLRs. The activation of microglia leads to the release of important pro-inflammatory cytokines, including TNF- $\alpha$ (43) and various ILs $(44,45)$. While mRNA for all TLRs can be detected in the brain, TLR2 and TLR4 are most highly expressed (46). It is increasingly clear that post-stroke neuroinflammation due to TLR4 signaling aggravates stroke outcome as measured by infarct volumes, neurological function and inflammatory markers (47-49). Several models of cerebral ischemia have identified the role of TLR4 signaling in neuroinflammation and exacerbated stroke injury. TLR4-deficient mice exhibit improved neurological and/or behavioral outcomes in various models of cerebral infarction $(50,51)$. It has been shown that TLR2 is responsible for part of the damaging inflammatory response that follows cerebral ischemia (52). Consistent with previous studies, our results revealed that TLR2 was responsible for the production of pro-inflammatory cytokines from microglia in cerebral I/R.

Recently, the role of both Sphks in immunity and inflammation has been the focus of multiple studies $(20,35,53,54)$, which suggest a broader role for Sphks. A study by Puneet and colleagues demonstrated that Sphk1 inhibition led to decreased phagocyte production of endotoxin-induced pro-inflammatory cytokines (55). Other studies revealed that the inhibition of Sphk1 by its inhibitor and/or siRNA decreased the expression of pro-inflammatory cytokines, such as TNF- $\alpha$, IL-1 $\beta$ and iNOS; when activated by LPS, microglial cells release these chemokines (28). In this study, Sphk1 expression in microglia was induced by cerebral I/R, triggering the inflammatory response in the process.

TNF- $\alpha$ and IL- $1 \beta$ are probably the most extensively studied cytokines in experimental stroke and are upregulated early in peri-infarct microglia along with IL-17 and IL-23 $(12,56)$. However, microglial activation requires hours to days to fully develop in brain ischemic injury (42), and the increases in cytokine mRNA and protein levels are at most moderate during the first $4.5 \mathrm{~h}$ after ischemia (56). Based on the results of our experiments, the protein expression of pro-inflammatory cytokines, including TNF- $\alpha$, IL-17 and IL-23, displayed almost the same patterns as TLR2 and Sphk1 in cerebral I/R. IL-1 $\beta$ seemed to increase earlier than the other cytokines, and the elevated level of IL-1 $\beta$ remained from 12 to $24 \mathrm{~h}$ after reperfusion. The above-mentioned results indicate that it takes at least 12 to $24 \mathrm{~h}$ for microglial activation to progress and release proinflammatory cytokines. Moreover, higher levels of cytokines may continue within $48 \mathrm{~h}$ from ischemia, which is in accordance with previous reports $(12,56)$.

Previous research has indicated that cerebral ischemia upregulates TLR2 and TLR4 expression (57-59), and the increase of TLR2 is more significant than that of TLR4 $(9,60,61)$. TLRs activate the endogenous immune system to release pro-inflammatory factors (e.g., IL- $\beta$ ) through the NF-кB pathway (31-34). The expression of Sphk1 in amoeboid microglia has been shown to be upregulated in post-natal rats under hypoxic conditions, which also promotes IL- $\beta$ and TNF- $\alpha$ production via the NF- $\kappa$ B pathway (29). Therefore, a common downstream pathway is activated following TLR2 and Sphk1 expression under ischemic conditions. In addition, studies on cultured human gingival epithelial cells, RAW264.7 macrophages, 293 cells, and human bone marrow-derived macrophages (THP-1) have revealed a close association between TLRs and Sphk1. Ligands of either TLR 2 or TLR4 are able to activate Sphk1 by elevating transcription levels of Sphk1, increasing its activity, and inducing membrane translocation (62-65). Therefore, it is reasonable to infer that cerebral ischemia can increase TLR2 expression, which further activates Sphk1 to promote the release of IL- $\beta$, $\mathrm{TNF}-\alpha$, and other pro-inflammatory cytokines via the NF- $\kappa \mathrm{B}$ pathway. In this study, the Sphk1 levels were decreased by antiTLR2 antibody, which downregulated TLR2 activity. However, DMS did not affect TLR2 expression by inhibiting Sphk1 activity. Our results confirm the role of TLR2 as a positive regulator of Sphk1 in cerebral I/R.

In conclusion, to the best of our knowledge, this is the first study to describe the involvement of microglial cells in inflammatory reactions via a TLR $2 \rightarrow$ Sphk $1 \rightarrow$ pro-inflammatory cytokine (IL-23, IL-17, IL-1 $\beta$ and TNF- $\alpha$ ) pathway in cerebral IRI. Microglial activation presents a target for therapeutic intervention with a much longer window of opportunity than can be achieved with current treatments. Effective agents are now available for blocking both the activation of TLR2 and the response of Sphk1 that drive the inflammatory response after stroke. Effective agents are also available for targeting the signal transduction mechanisms between TLR2 and Sphk1 or between TLR2/Sphk1 and pro-inflammatory cytokines. However, the innate immune response can exert both beneficial and deleterious effects on stroke outcome, and it will be challenging to find ways to selectively suppress the deleterious effects of microglial activation after stroke without compromising neurovascular repair and remodeling.

\section{Acknowledgements}

This study was supported by the Postdoctoral Foundation of Heilongjiang Province of China (no. LBH-Z10065) and the Open Project of Neurobiology Key Laboratory in General Institutes of Higher Education of Heilongjiang Province of China.

\section{References}

1. Donnan GA, Fisher M, Macleod M and Davis SM: Stroke. Lancet 371: 1612-1623, 2008.

2. Huang Y, Rabb H and Womer KL: Ischemia-reperfusion and immediate T cell responses. Cell Immunol 248: 4-11, 2007.

3. Muir KW, Tyrrell P, Sattar N and Warburton E: Inflammation and ischaemic stroke. Curr Opin Neurol 20: 334-342, 2007.

4. Olson JK and Miller SD: Microglia initiate central nervous system innate and adaptive immune responses through multiple TLRs. J Immunol 173: 3916-3924, 2004.

5. Dirnagl U, Iadecola C and Moskowitz MA: Pathobiology of ischaemic stroke: An integrated view. Trends Neurosci 22: 391-397, 1999.

6. Block ML and Hong JS: Microglia and inflammation-mediated neurodegeneration: Multiple triggers with a common mechanism. Prog Neurobiol 76: 77-98, 2005. 
7. Block ML, Zecca L and Hong JS: Microglia-mediated neurotoxicity: Uncovering the molecular mechanisms. Nat Rev Neurosci 8: 57-69, 2007.

8. Lehnardt S: Innate immunity and neuroinflammation in the CNS The role of microglia in Toll-like receptor-mediated neurona injury. Glia 58: 253-263, 2010.

9. Lehnardt S, Henneke P, Lien E, Kasper DL, Volpe JJ, Bechmann I, Nitsch R, Weber JR, Golenbock DT and Vartanian T: A mechanism for neurodegeneration induced by group B streptococci through activation of the TLR2/MyD88 pathway in microglia. J Immunol 177: 583-592, 2006.

10. Li Y, Chu N, Hu A, Gran B, Rostami A and Zhang GX: Increased IL-23p19 expression in multiple sclerosis lesions and its induction in microglia. Brain 130: 490-501, 2007.

11. Li Y, Chu N, Hu A, Gran B, Rostami A and Zhang GX: Inducible IL-23p19 expression in human microglia via p38 MAPK and NF-kappaB signal pathways. Exp Mol Pathol 84: 1-8, 2008.

12. Lv M, Liu Y, Zhang J, Sun L, Liu Z, Zhang S, Wang B, Su D and $\mathrm{Su} \mathrm{Z}$ : Roles of inflammation response in microglia cell through Toll-like receptors $2 /$ interleukin-23/interleukin-17 pathway in cerebral ischemia/reperfusion injury. Neuroscience 176: 162-172, 2011.

13. Alemany R, van Koppen CJ, Danneberg K, Ter Braak M and Meyer Zu Heringdorf D: Regulation and functional roles of sphingosine kinases. Naunyn Schmiedebergs Arch Pharmacol 374 413-428, 2007.

14. Okada T, Kajimoto T, Jahangeer S and Nakamura S: Sphingosine kinase/sphingosine 1-phosphate signalling in central nervous system. Cell Signal 21: 7-13, 2009.

15. Ozaki H, Hla T and Lee MJ: Sphingosine-1-phosphate signaling in endothelial activation. J Atheroscler Thromb 10: 125-131, 2003.

16. Rosen H and GoetzlEJ: Sphingosine 1-phosphate and its receptors: An autocrine and paracrine network. Nat Rev Immunol 5: 560-570, 2005

17. Alvarez SE, Milstien S and Spiegel S: Autocrine and paracrine roles of sphingosine-1-phosphate. Trends Endocrinol Metab 18 300-307, 2007.

18. Gude DR, Alvarez SE, Paugh SW, Mitra P, Yu J, Griffiths R Barbour SE, Milstien S and Spiegel S: Apoptosis induces expression of sphingosine kinase 1 to release sphingosine-1-phosphate as a 'come-and-get-me' signal. FASEB J 22: 2629-2638, 2008.

19. Hammad SM, Crellin HG, Wu BX, Melton J, Anelli V and Obeid LM: Dual and distinct roles for sphingosine kinase 1 and sphingosine 1 phosphate in the response to inflammatory stimuli in RAW macrophages. Prostaglandins Other Lipid Mediat 85: $107-114,2008$

20. Melendez AJ: Sphingosine kinase signalling in immune cells: Potential as novel therapeutic targets. Biochim Biophys Acta 1784 66-75, 2008.

21. Haghikia A and Gold R: Sphingosine-1-phosphate and its receptors as a possible therapeutic target in autoimmune diseases of the nervous system. J Neuroimmunol 218: 1-2, 2010.

22. Bryan L, Kordula T, Spiegel S and Milstien S: Regulation and functions of sphingosine kinases in the brain. Biochim Biophys Acta 1781: 459-466, 2008.

23. Hait NC, Oskeritzian CA, Paugh SW, Milstien S and Spiegel S: Sphingosine kinases, sphingosine 1-phosphate, apoptosis and diseases. Biochim Biophys Acta 1758: 2016-2026, 2006

24. Ibrahim FB, Pang SJ and Melendez AJ: Anaphylatoxin signaling in human neutrophils. A key role for sphingosine kinase. J Biol Chem 279: 44802-44811, 2004.

25. Blondeau N, Lai Y, Tyndall S, Popolo M, Topalkara K, Pru JK, Zhang L, Kim H, Liao JK, Ding K, et al: Distribution of sphingosine kinase activity and mRNA in rodent brain. J Neurochem 103: 509-517, 2007.

26. Fukuda Y, Kihara A and Igarashi Y: Distribution of sphingosine kinase activity in mouse tissues: Contribution of SPHK1. Biochem Biophys Res Commun 309: 155-160, 2003.

27. Tham CS, Lin FF, Rao TS, Yu N and Webb M: Microglial activation state and lysophospholipid acid receptor expression. Int J Dev Neurosci 21: 431-443, 2003.

28. Nayak D, Huo Y, Kwang WX, Pushparaj PN, Kumar SD, Ling EA and Dheen ST: Sphingosine kinase 1 regulates the expression of proinflammatory cytokines and nitric oxide in activated microglia. Neuroscience 166: 132-144, 2010.

29. Lin H,Baby N, Lu J, Kaur C, Zhang C, Xu J, Ling EA and Dheen ST: Expression of sphingosine kinase 1 in amoeboid microglial cells in the corpus callosum of postnatal rats. J Neuroinflammation 8: $13,2011$.
30. Maceyka M, Payne SG, Milstien S and Spiegel S: Sphingosine kinase, sphingosine-1-phosphate, and apoptosis. Biochim Biophys Acta 1585: 193-201,2002.

31. Aliprantis AO, Yang RB, Weiss DS, GodowskiP and Zychlinsky A: The apoptotic signaling pathway activated by Toll-like receptor- 2 . EMBO J 19: 3325-3336, 2000.

32. Karikó K, Weissman D and Welsh FA: Inhibition of Toll-like receptor and cytokine signaling - a unifying theme in ischemic tolerance. J Cereb Blood Flow Metab 24: 1288-1304, 2004.

33. Kielian T: Toll-like receptors in central nervous system glial inflammation and homeostasis. J Neurosci Res 83: 711-730, 2006.

34. Zhang G and Ghosh S: Toll-like receptor-mediated NF-kappaB activation: A phylogenetically conserved paradigm in innate immunity. J Clin Invest 107: 13-19, 2001.

35. Wu W, Mosteller RD and Broek D: Sphingosine kinase protects lipopolysaccharide-activated macrophages from apoptosis. Mol Cell Biol 24: 7359-7369, 2004.

36. Neumann J, Sauerzweig S, Rönicke R, Gunzer F, Dinkel K, Ullrich O, Gunzer M and Reymann KG: Microglia cells protect neurons by direct engulfment of invading neutrophil granulocytes: A new mechanism of CNS immune privilege. J Neurosci 28 : 5965-5975, 2008

37. Colton CA and Gilbert DL: Production of superoxide anions by a CNS macrophage, the microglia. FEBS Lett 223: 284-288, 1987.

38. Lee SC, Liu W, Dickson DW, Brosnan CF and Berman JW: Cytokine production by human fetal microglia and astrocytes. Differential induction by lipopolysaccharide and IL-1 beta. J Immunol 150: 2659-2667, 1993.

39. Moss DW and Bates TE: Activation of murine microglial cell lines by lipopolysaccharide and interferon-gamma causes NO-mediated decreases in mitochondrial and cellular function. Eur J Neurosci 13: 529-538, 2001.

40. Liu B, Gao HM, Wang JY, Jeohn GH, Cooper CL and Hong JS: Role of nitric oxide in inflammation-mediated neurodegeneration. Ann NY Acad Sci 962: 318-331, 2002

41. Sawada M, Kondo N, Suzumura A and Marunouchi T: Production of tumor necrosis factor-alpha by microglia and astrocytes in culture. Brain Res 491: 394-397, 1989.

42. Yenari MA, Kauppinen TM and Swanson RA: Microglial activation in stroke: Therapeutic targets. Neurotherapeutics 7: 378-391, 2010.

43. Lambertsen KL, Meldgaard M, Ladeby R and Finsen B: A quantitative study of microglial-macrophage synthesis of tumor necrosis factor during acute and late focal cerebral ischemia in mice. J Cereb Blood Flow Metab 25: 119-135, 2005.

44. Minami M, Kuraishi Y, Yabuuchi K, Yamazaki A and Satoh M Induction of interleukin-1 beta mRNA in rat brain after transient forebrain ischemia. J Neurochem 58: 390-392, 1992.

45. Block F, Peters M and Nolden-Koch M: Expression of IL-6 in the ischemic penumbra. Neuroreport 11: 963-967, 2000.

46. Nishimura M and Naito S: Tissue-specific mRNA expression profiles of human Toll-like receptors and related genes. Biol Pharm Bull 28: 886-892, 2005.

47. Caso JR, Pradillo JM, Hurtado O, Lorenzo P, Moro MA and Lizasoain I: Toll-like receptor 4 is involved in brain damage and inflammation after experimental stroke. Circulation 115: $1599-1608,2007$

48. Abate W, Alghaithy AA, Parton J, Jones KP and Jackson SK: Surfactant lipids regulate LPS-induced interleukin-8 production in A549 lung epithelial cells by inhibiting translocation of TLR4 into lipid raft domains. J Lipid Res 51: 334-344, 2010.

49. Tasaki K, Ruetzler CA, Ohtsuki T, Martin D, Nawashiro H and Hallenbeck JM: Lipopolysaccharide pre-treatment induces resistance against subsequent focal cerebral ischemic damage in spontaneously hypertensive rats. Brain Res 748: 267-270, 1997.

50. Hua F, Ma J, Ha T, Xia Y, Kelley J, Williams DL, Kao RL, Browder IW, Schweitzer JB, Kalbfleisch JH, et al: Activation of Toll-like receptor 4 signaling contributes to hippocampal neuronal death following global cerebral ischemia/reperfusion. J Neuroimmunol 190: 101-111, 2007.

51. Cao CX, Yang QW, Lv FL, Cui J, Fu HB and Wang JZ: Reduced cerebral ischemia-reperfusion injury in Toll-like receptor 4 deficient mice. Biochem Biophys Res Commun 353: 509-514, 2007.

52. Ziegler G, Harhausen D, Schepers C, Hoffmann O, Röhr C, Prinz V, König J, Lehrach H, Nietfeld W and Trendelenburg G: TLR2 has a detrimental role in mouse transient focal cerebral ischemia. Biochem Biophys Res Commun 359: 574-579, 2007.

53. Lai WQ, Goh HH, Bao Z, Wong WS, Melendez AJ and Leung BP: The role of sphingosine kinase in a murine model of allergic asthma. J Immunol 180: 4323-4329, 2008. 
54. Snider AJ, Kawamori T, Bradshaw SG, Orr KA, Gilkeson GS, Hannun YA and Obeid LM: A role for sphingosine kinase 1 in dextran sulfate sodium-induced colitis. FASEB J 23: 143-152, 2009.

55. Puneet P, Yap CT, Wong L, Lam Y, Koh DR, Moochhala S, Pfeilschifter J, Huwiler A and Melendez AJ: SphK1 regulates proinflammatory responses associated with endotoxin and polymicrobial sepsis. Science 328: 1290-1294, 2010.

56. Lambertsen KL, Biber K and Finsen B: Inflammatory cytokines in experimental and human stroke. J Cereb Blood Flow Metab 32: $1677-1698,2012$.

57. Lehnardt S, Lehmann S, Kaul D, Tschimmel K, Hoffmann O, Cho S, Krueger C, Nitsch R, Meisel A and Weber JR: Toll-like receptor 2 mediates CNS injury in focal cerebral ischemia. J Neuroimmunol 190: 28-33, 2007.

58. Caso JR, Pradillo JM, Hurtado O, Leza JC, Moro MA and Lizasoain I: Toll-like receptor 4 is involved in subacute stress-induced neuroinflammation and in the worsening of experimental stroke. Stroke 39: 1314-1320, 2008.

59. Kilic U, Kilic E, Matter CM, Bassetti CL and Hermann DM: TLR-4 deficiency protects against focal cerebral ischemia and axotomy-induced neurodegeneration. Neurobiol Dis 31: 33-40, 2008.

60. Hoffmann O, Braun JS, Becker D, Halle A, Freyer D, Dagand E, Lehnardt $S$ and Weber JR: TLR2 mediates neuroinflammation and neuronal damage. J Immunol 178: 6476-6481, 2007.
61. Mishra BB, Mishra PK and Teale JM: Expression and distribution of Toll-like receptors in the brain during murine neurocysticercosis. J Neuroimmunol 181: 46-56, 2006.

62. Benakanakere MR, Zhao J, Galicia JC, Martin M and Kinane DF: Sphingosine kinase-1 is required for toll mediated beta-defensin 2 induction in human oral keratinocytes. PLoS One 5: e11512, 2010

63. Pitson SM, Moretti PA, Zebol JR, Lynn HE, Xia P, Vadas MA and Wattenberg BW: Activation of sphingosine kinase 1 by ERK1/2-mediated phosphorylation. EMBO J 22: 5491-5500, 2003.

64. Spiegel S and Milstien S: Sphingosine-1-phosphate: An enigmatic signalling lipid. Nat Rev Mol Cell Biol 4: 397-407, 2003.

65. Pchejetski D, Nunes J, Coughlan K, Lall H, Pitson SM, Waxman J and Sumbayev VV: The involvement of sphingosine kinase 1 in LPS-induced Toll-like receptor 4-mediated accumulation of HIF- $1 \alpha$ protein, activation of ASK1 and production of the pro-inflammatory cytokine IL-6. Immunol Cell Biol 89: 268-274, 2011.

This work is licensed under a Creative Commons Attribution-NonCommercial-NoDerivatives 4.0 International (CC BY-NC-ND 4.0) License. 